\title{
0 projeto da habitação de interesse social e a sustentabilidade social
}

\author{
Social housing design and social sustainability
}

\begin{tabular}{|c|c|}
\hline & $\begin{array}{l}\text { Antônio Tarcísio da Luz Reis } \\
\text { Maria Cristina Dias Lay }\end{array}$ \\
\hline $\begin{array}{r}\text { Antônio Tarcísio da Luz } \\
\text { Reis }\end{array}$ & $\begin{array}{l}\text { Resumo } \\
\text { objetivo deste artigo é reforçar a importância da sustentabilidade } \\
\text { social para o projeto da habitação de interesse social e apontar } \\
\text { recomendações projetuais que possuam o potencial de qualificar a } \\
\text { habitação de interesse social, com base em investigações realizadas. A } \\
\text { qualidade das soluções arquitetônicas envolvendo os aspectos estéticos e } \\
\text { funcionais do projeto da habitação social determina a eficiência com que o projeto } \\
\text { responde às necessidades de seus usuários. Projetos habitacionais para a população } \\
\text { de baixa renda da região metropolitana de Porto Alegre são utilizados como objeto } \\
\text { de estudo. A análise dos dados obtidos através de questionários, entrevistas, } \\
\text { observações de comportamento e traços físicos e levantamentos físicos, possibilita } \\
\text { a produção da informação necessária. Os resultados revelam a importância da } \\
\text { consideração dos aspectos físico-espaciais para a qualidade e conseqüiente } \\
\text { sustentabilidade do projeto da habitação de interesse social. Por exemplo, as } \\
\text { relações entre as edificações e os espaços abertos tende a afetar o uso e adequação } \\
\text { de tais espaços e, logo, a existência de um ambiente residencial socialmente } \\
\text { sustentável. }\end{array}$ \\
\hline $\begin{array}{r}\text { Departamento de Arquitetura, } \\
\text { Faculdade de Arquitetura } \\
\text { Universidade Federal do Rio } \\
\text { Grande do Sul }\end{array}$ & $\begin{array}{l}\text { Palavras-chave: Projeto da habitação. Habitação de Interesse Social. Sustentabilidade } \\
\text { social. }\end{array}$ \\
\hline $\begin{array}{r}\text { Rua Sarmento Leite, 320, } \\
\text { Farroupilha }\end{array}$ & Abstract \\
\hline $\begin{array}{r}\text { Porto Alegre - RS - Brasil } \\
\text { CEP 90050-170 } \\
\text { Tel.: (51) 3308-3152 } \\
\text { E-mail: tarcisio@orion.ufrgs.br }\end{array}$ & $\begin{array}{l}\text { The aim of this paper is to strengthen the importance of social sustainability for } \\
\text { social housing and to propose design recommendations that have the potential to } \\
\text { qualify social housing. The quality of architectural solutions involving the } \\
\text { aesthetic and functional aspects of social housing design determines the }\end{array}$ \\
\hline $\begin{array}{l}\text { Maria Cristina Dias Lay } \\
\text { Departamento de Urbanismo, } \\
\text { Faculdade de Arquitetura } \\
\text { Universidade Federal do Rio }\end{array}$ & $\begin{array}{l}\text { effectiveness with which such design meets the needs of its users. Housing estates } \\
\text { for low-income populations of the metropolitan region of Porto Alegre have been } \\
\text { used as study objects. The analysis of the data obtained through questionnaires, }\end{array}$ \\
\hline $\begin{array}{r}\text { Grande do Sul } \\
\text { Rua Sarmento Leite, } 320, \\
\text { Farroupilha } \\
\text { Porto Alegre - RS - Brasil }\end{array}$ & $\begin{array}{l}\text { interviews, observation of behavior and physical traces, and physical } \\
\text { measurements allows the production of the necessary information. The results } \\
\text { reveal the importance of considering the physical-spatial aspects of quality and the }\end{array}$ \\
\hline $\begin{array}{r}\text { CEP 90050-170 } \\
\text { Tel.: (51) 3308-3152 } \\
\text { E-mail: cristina.lay@ufrgs.br }\end{array}$ & $\begin{array}{l}\text { resulting sustainability of the social housing design. For example, the relationship } \\
\text { between buildings and open spaces tends to affect the use and suitability of such } \\
\text { areas, and consequently the existence of a socially sustainable residential }\end{array}$ \\
\hline cedia & \\
\hline $18 / 08 / 10$ & cial housin. Social sustainability. \\
\hline
\end{tabular}




\section{Introdução}

A habitação de interesse social está associada diretamente à necessidade de prover habitação urbana para os setores menos favorecidos da população. Tal habitação pode ser provida pelo setor público ou privado, para fins de venda ou aluguel aos seus moradores (BLAY, 1985; FRANCESCATO et al., 1979; LAY, 2001; LEITE, 2005; REIS, 1992). A falta de habitações destinadas à população de baixa renda começou nas cidades da Inglaterra, para posteriormente ocorrer no restante da Europa. Na metade do século XIX, como consequência da Revolução Industrial, as cidades britânicas já haviam recebido grande quantidade de pessoas provenientes do meio rural, que tendiam a se alojar em habitações alugadas ou mesmo em habitações invadidas, muitas densamente ocupadas e em condições precárias em termos de salubridade e tamanho (RYKWERT, 2004). No Brasil, a habitação social surge como consequência da demanda de um grande número de habitações em decorrência de migrações acentuadas do meio rural para as cidades a partir de 1950, em função, fundamentalmente, da industrialização acelerada, assim como do próprio crescimento significativo da população brasileira (REIS, 1992). No final da década de 50, a população urbana brasileira já era $70 \%$ maior do que no começo daquela década. O crescimento acentuado se manteve nas décadas seguintes, fazendo com que a população urbana crescesse $321 \%$ em 30 anos, de menos de 19 milhões em 1950 para mais de 80 milhões em 1980, partindo de $45 \%$ do total da população brasileira em 1960 para $67 \%$ do total da população em 1980. Por sua vez, a população brasileira cresceu de 52 milhões em 1950 para 119 milhões em 1980 (um aumento de $128 \%$ em 30 anos). Esses números refletem a magnitude do problema gerado com a falta de habitações, provocando a proliferação de cortiços e de precárias habitações autoconstruídas, normalmente nas periferias urbanas, que viriam a constituir as favelas (SERRA, 1989). Embora exista um declínio no percentual do déficit habitacional (por exemplo, de 16,1\% em 2004 para 14,5\% em 2006 , e para $10,1 \%$ em 2008), indicando que o crescimento do déficit habitacional em números absolutos se deu em ritmo menor do que o crescimento dos domicílios nos últimos anos, o mesmo continua a ser expressivo. Por exemplo, o déficit habitacional estimado em 2006 era de 7,935 milhões de domicílios, 6,543 milhões $(82,5 \%)$ em áreas urbanas (MINISTÉRIO DAS CIDADES, 2010a; 2010b). Esse déficit foi reduzido para 6,3 milhões em 2007 e para 5,8 milhões de domicílios em 2008, conforme anunciado pelo Ministério das Cidades (junho de 2010) em 22 de março de 2010.
Desse déficit de domicílios, 4,756 (82\%) estão localizados nas áreas urbanas. Esses dados evidenciam a necessidade de construção de um grande número de habitações de interesse social para uma parcela expressiva da população, que não possui recursos financeiros para adquirir uma moradia comercializada pelo setor privado. Contudo, além dos aspectos quantitativos, é importante que os aspectos relacionados à qualidade da habitação de interesse social também sejam considerados, o que remete à sustentabilidade social.

Sustentabilidade social é uma das três dimensões do conceito de "desenvolvimento sustentável", também constituído pela dimensão ecológica (ou ambiental) e econômica (LEGENDRE, 2003; REIS, 2002; SILVA, 2007). O conceito de sustentabilidade implica a existência de um balanço entre os aspectos econômicos, ambientais (ou ecológicos) e sociais (WHITE; ELLIS, 2007). Portanto, não basta, por exemplo, haver sustentabilidade ecológica (tal como a redução do gasto de energia em uma habitação) se não houver sustentabilidade social (tal como um adequado nível de privacidade visual no interior de uma habitação). Esta também é fundamental, pois o desenvolvimento sustentável é um complexo de valores culturais, aspectos éticos, atitudes e comportamentos humanos além dos aspectos ecológicos a serem considerados na formulação de estratégias para soluções efetivas e aceitáveis, incluindo os interesses e a qualidade de vida dos indivíduos e das comunidades locais (SADAN; CHURCHMAN, 1996). Neste sentido, “[...] os problemas da super-exploração ambiental estão sendo reconhecidos como não somente problemas físico-químicos, biológicos ou técnicos, mas, significativamente, como problemas sóciocomportamentais." (SADAN; CHURCHMAN, 1996, p. 184).

Conforme salientado por Kruse (1997, p. 11), o conceito de "sustentabilidade social" deve considerar as pessoas como "seres culturais", ultrapassando a noção de seres humanos "como organismos que vivem com base num mínimo de necessidades diárias de calorias e água”. Assim, a sustentabilidade social trata, por exemplo, de oportunidades iguais para os seres humanos, dos padrões de atividades em diferentes contextos culturais e sociais nos quais as pessoas vivem e dos padrões de comportamento relacionados à mobilidade, experiência habitacional, trabalho e relações sociais (KRUSE, 1997). Logo, o desenvolvimento sustentável também implica “[...] melhoria da qualidade de vida dos seres humanos, 
nos níveis urbanos e arquitetônicos, dentro da capacidade do eco-sistema global [...]" (OKTAY, 1999, p. 147). Assim, a sustentabilidade social diz sobre a adequação dos locais onde as relações sociais se desenvolvem (LEGENDRE, 2003). Fazem parte dos temas-chave para uma construção socialmente sustentável na Grã-Bretanha “"[...] edifícios e estruturas que aumentem a satisfação, o bem-estar e o valor para clientes e usuários [...]" (SILVA, 2007, p. 57). Mais especificamente, a sustentabilidade social trata também de indicadores tais como acessibilidade, qualidade estética arquitetônica, flexibilidade da edificação, ambiente interno e adequação ao entorno (SILVA, 2007).

Nesse sentido, o projeto da habitação de interesse social está diretamente relacionado à sustentabilidade social, além das sustentabilidades ecológica e econômica. Projetos habitacionais sustentáveis implicariam a melhoria da qualidade de vida dos residentes mediante o uso adequado dos recursos naturais locais e uma abordagem de projeto contextual respeitando sítio, clima, características culturais e necessidades humanas (OKTAY, 1999). Logo, a habitação de interesse social sustentável não pode ser pensada exclusivamente como a possibilidade de uso adequado dos recursos naturais, mas deve incluir um projeto habitacional qualificado que propicie um comportamento humano adequado e a satisfação dos residentes, considerando os vários aspectos pertinentes à produção de projetos habitacionais. Entretanto, a habitação de interesse social tem deixado de ser sustentável não apenas em sua dimensão ecológica e econômica mas também em sua dimensão social, no que diz respeito à qualidade de seu projeto arquitetônico e de desenho urbano (LAY, 1992; REIS, 1992, 1999).

Embora existissem contradições no passado acerca do papel e da importância desempenhada por aspectos de projeto sobre a qualidade da habitação de interesse social e consequente bem-estar de seus moradores, parece que hoje é reconhecido que nem a "visão de determinismo arquitetônico" nem a "visão de determinismo social" são aceitáveis como reveladoras da complexidade das causas envolvidas (LAY, 1992). Essas visões são representadas, respectivamente, pela crença de Alice Coleman (1985) de que os problemas da habitação de interesse social estão exclusivamente relacionados ao projeto, descartando qualquer influência de fatores sociais e econômicos, e pela posição de Baldwin (1975), que considera que os problemas apontados não decorrem da arquitetura ou de aspectos de projeto, mas de aspectos sociais e administrativos da habitação de interesse social. Assim, embora a qualidade do projeto arquitetônico não determine a qualidade e a consequente sustentabilidade da habitação de interesse social, esta é afetada pela qualidade de seu projeto. Nesse sentido, as demolições dos conjuntos habitacionais Pruitt-Igoe, em St. Louis, Missouri, Estados Unidos (BLAKE, 1977; MONTGOMERY, 1977), e Killingworth (KELLET, 1987), no norte da Inglaterra, atestam os efeitos negativos de tais projetos sobre seus residentes, também portadores de problemas econômicos e sociais. Por exemplo, no caso do premiado conjunto Killingworth, demolido 15 anos após sua construção (Figura 1), constituído por 740 apartamentos (3.292 moradores) em 27 blocos com 6 e 10 pavimentos, fica claro o impacto negativo gerado pela aparência pouco atraente e monótona do conjunto de blocos e pelo sistema de circulação com as passarelas elevadas, que, por exemplo, dificultavam a supervisão dos transeuntes e facilitavam ações de vandalismo. Esses e outros problemas de natureza projetual, somados aos problemas socioeconômicos de muitos residentes, geraram uma situação crítica que culminou com a demolição do conjunto (KELLET, 1987).

No Brasil, pode ser mencionado como problemático, por exemplo, o conjunto Rubem Berta (Figura 2), em Porto Alegre, com 4.992 apartamentos em blocos de quatro pavimentos, que provocou manifestações sobre os problemas por parte dos residentes, tais como "[...] a política brasileira de habitação pensa somente em prover um teto, um lugar para viver e nada mais; eles não pensam sobre outras coisas [...]”; “[...] quem quer que seja que tenha feito o projeto do Rubem Berta pensou que o mesmo era para pessoas pobres, então projetou para eles terem somente um teto, sem se preocupar sobre o mesmo[...]"; e "[...] já que somos pobres nós deveríamos receber uma habitação melhor na qual nós não precisaríamos gastar dinheiro [fazendo alterações] [...]” (REIS, 1992). 


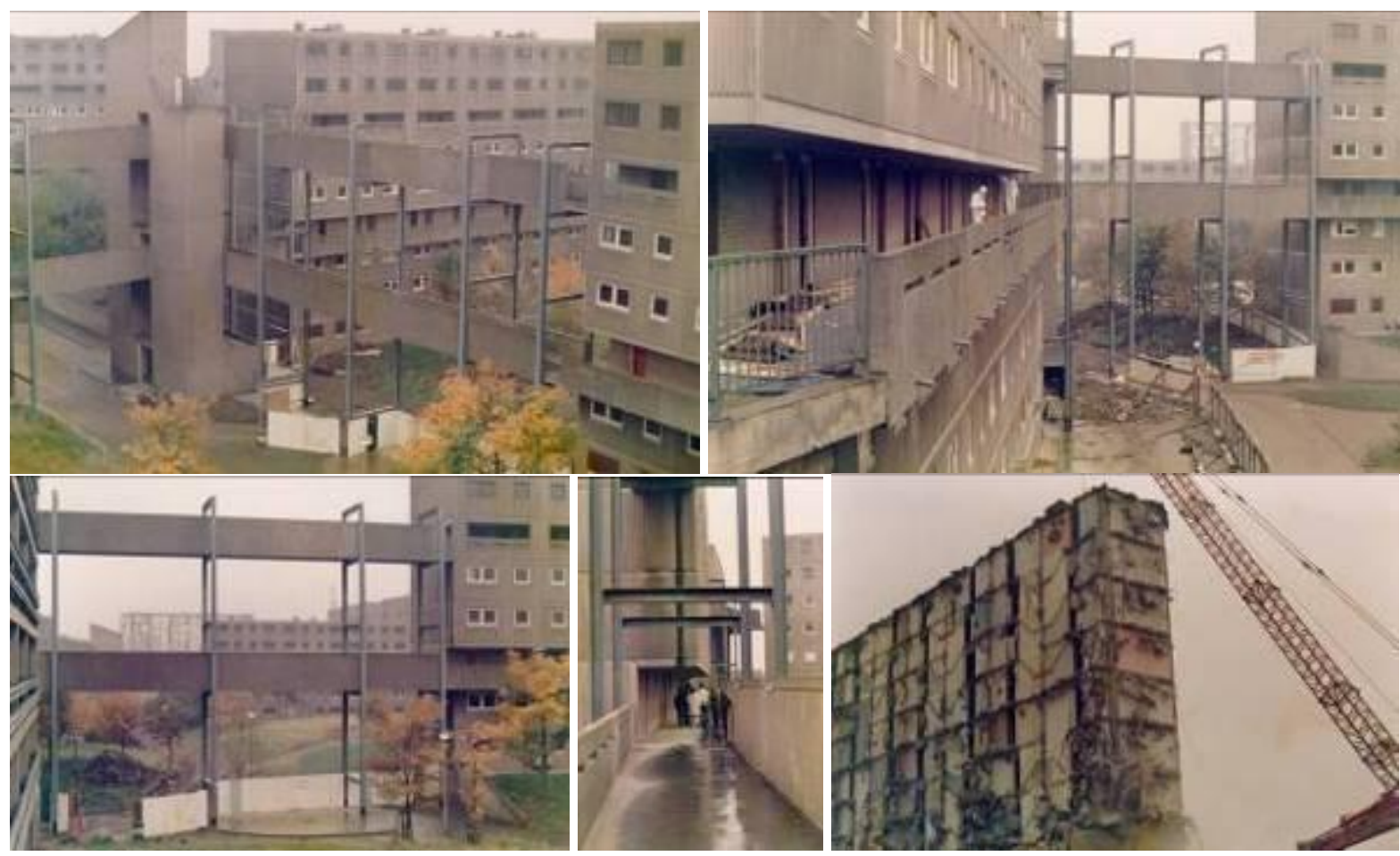

Figura 1 - Conjunto habitacional Killingworth em processo de demolição

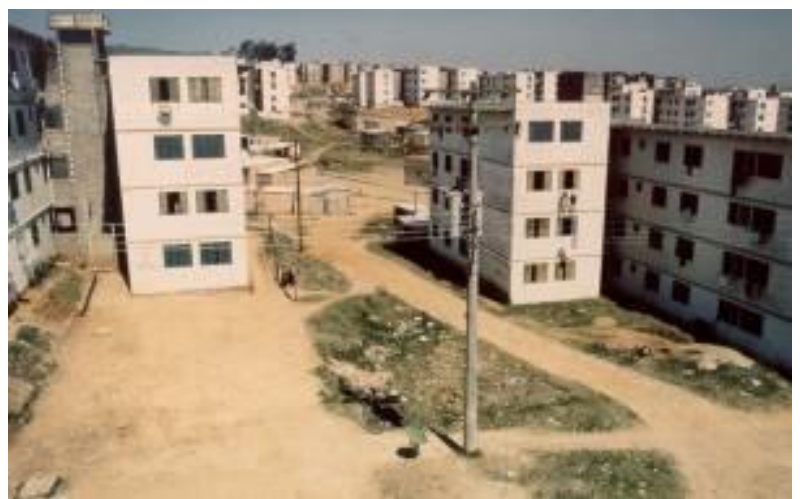

Figura 2 - Conjunto Rubem Berta

Nesse sentido, Francescato et al. (1979) salientam que a satisfação dos usuários com a habitação de interesse social é influenciada por aspectos físicos e não físicos. Assim, sem minimizar ou desconsiderar o efeito de outros aspectos, fica claro que os aspectos físico-espaciais ou aspectos de projeto desempenham um papel importante na qualidade da habitação de interesse social e, particularmente, no que tange a sua sustentabilidade social (LAY, 1992; REIS, 1992). Embora a importância de tais aspectos tenha sido reconhecida e traduzida em pesquisas, conferências nacionais (p. ex., Encontro Nacional de Tecnologia do Ambiente Construído - ENTAC) e internacionais (p. ex., International Association for People-Environment Studies - IAPS; Environmental Design Research Association EDRA) e periódicos científicos nacionais (p. ex.,

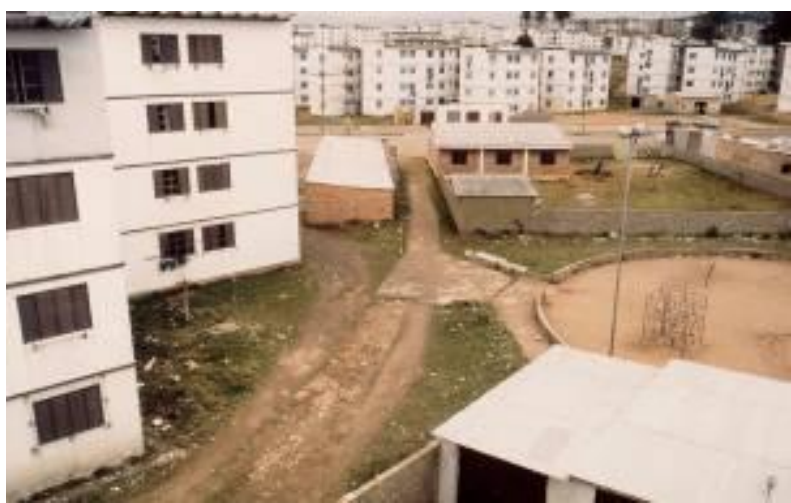

Revista Ambiente Construído) e internacionais (p. ex., Environment and Behavior, Journal of Architectural and Planning Research), ainda existe a necessidade de realizar mais pesquisas e maior divulgação dos resultados para que tanto acadêmicos quanto aqueles envolvidos com a produção da habitação de interesse social possam canalizar tais conhecimentos na melhoria dos projetos habitacionais. Assim, o fato de que além de ecológica e economicamente sustentável, a habitação de interesse social deva ser socialmente sustentável, e responda adequadamente às necessidades dos moradores em suas várias dimensões, requer um entendimento apropriado das relações entre tais necessidades e as características físicas das habitações. Contudo, tal abordagem projetual parece estar longe de ser aceita e incorporada sistematicamente no projeto 
da habitação de interesse social, pelo menos no Brasil, conforme pode ser exemplificado por projetos habitacionais mais recentes que fazem parte do Programa de Arrendamento Residencial (PAR), no Rio Grande do Sul (LEITE, 2005). Logo, embora muita pesquisa já tenha sido realizada e seus resultados publicados em periódicos, livros, anais de congressos, dissertações de mestrado, teses de doutorado e relatórios (COOPER-MARCUS; SARKISSIAN, 1986; FRANCESCATO et al. 1979; LAY, 1992; REIS, 1992, 1999; REIS; LAY, 1995), é necessário, principalmente no caso da habitação de interesse social no Brasil, apresentar e divulgar resultados de pesquisa que evidenciem a importância da sustentabilidade social para a qualidade da habitação e que indiquem alternativas ou propostas de projeto que venham a qualificar a habitação de interesse social. $O$ projeto da habitação de interesse social tende a apresentar particularidades quando comparado ao projeto da habitação para os setores da população que têm acesso ao mercado imobiliário, por exemplo, no que diz respeito ao número normalmente expressivo de unidades habitacionais (muitas vezes, por exemplo, sem o tipo de conexões adequadas entre os espaços), às relações entre essas unidades e os espaços abertos (muitas vezes sem tratamento adequado) e à existência de equipamentos, serviços e comércio (muitas vezes inexistentes) (LAY, 1996; REIS, 1999). Decorre que o foco na sustentabilidade social do projeto da habitação de interesse social parece assumir maior relevância do que o do projeto da habitação para setores da população com maiores níveis de renda. Portanto, o objetivo deste artigo é reforçar a importância da sustentabilidade social para o projeto da habitação de interesse social e apresentar recomendações projetuais que possuam o potencial de qualificar a habitação de interesse social com base em investigações realizadas. Neste artigo, os aspectos abordados dizem respeito ao exterior das unidades habitacionais.

\section{Metodologia}

Os resultados aqui apresentados foram obtidos em investigações realizadas em 12 conjuntos habitacionais na região metropolitana de Porto Alegre, caracterizados por casas isoladas no terreno (Guajuviras e Costa e Silva), casas em fita (Costa e Silva), casas geminadas (Restinga), sobrados com dois pavimentos (Vale Verde, João Vedana, São Jorge e Santo Alfredo) e blocos de apartamentos com quatro pavimentos (Loureiro, Angico, Cavalhada, Guajuviras e Sapucaia). Originalmente, todas as casas tinham um pavimento. Contudo, após serem ocupadas, muitas sofreram alterações e algumas passaram a ter dois pavimentos. Os espaços abertos nos conjuntos com casas são públicos, com exceção dos pátios privados, e são caracterizados por ruas e praças. Nos condomínios fechados com sobrados os espaços abertos são semiprivados (exceto os diminutos jardins frontais e os pequenos pátios de fundos) e caracterizados por vias de circulação de pedestres e veículos, garagens e áreas com equipamentos de lazer. Nos conjuntos com blocos com quatro pavimentos os espaços abertos, embora com menor clareza de definição do que nos conjuntos com casas e sobrados, tendem a ser semipúblicos ou semiprivados e caracterizados por caminhos para pedestres, áreas de lazer e recreação, e frequentemente também pela ocupação dos espaços abertos comunais por construções para fins privados (por exemplo, garagens com churrasqueiras), além das ruas públicas que delimitam os conjuntos. Essas diferentes características dos espaços abertos nos diferentes conjuntos, incluindo o tipo de controle dos espaços por parte dos moradores, implicam em diferenças quanto a um conjunto de aspectos, como mostram os resultados.

Os dados foram coletados por meio de questionários aplicados a 374 respondentes (cada um sendo morador de uma distinta unidade habitacional), constituídos de perguntas fechadas com o objetivo de revelar as atitudes dos moradores em relação a aspectos físico-espaciais dos espaços abertos do conjunto. A definição da amostra de respondentes dos questionários teve por base a possibilidade de realização de testes estatísticos não paramétricos, que tendem a requerer amostras em torno de 30 ou mais respondentes, para que exista maior confiabilidade sobre a realização deles (LEEDY, 1989; REIS, 1992; LAY; REIS, 2005). Contudo, o tamanho das amostras nos conjuntos São Jorge e Santo Alfredo sofreram uma redução devido ao número de sobrados (52 e 40 respectivamente) e da ausência de vários moradores por motivos de férias. Assim, as amostras ficaram definidas conforme a Tabela 1 .

Os respondentes foram selecionados segundo a localização da moradia dentro do conjunto, em relação aos espaços abertos do conjunto, e graus de acessibilidade visual e funcional (distância do bloco e andar da moradia) existente entre sua moradia e os diferentes espaços abertos de uso coletivo. Ainda, foram realizadas entrevistas com o objetivo de permitir um aprofundamento e melhor entendimento de determinadas informações de caráter qualitativo fornecidas pelos moradores (VAN DALEN, 1979). Segue que a definição da quantidade de entrevistas está relacionada à 
possibilidade de obtenção de informações julgadas adequadas conforme os objetivos da investigação, assim como às questões operacionais, tais como quantidade de tempo para a coleta de dados e tempo de envolvimento por parte do entrevistado (REIS; LAY, 1995). Assim, com base no exposto, definiu-se o número de 9 a 10 entrevistas por conjunto, totalizando 111 entrevistas.

Observações de traços físicos que revelam vestígios deixados por atividades/comportamentos foram realizadas e registradas em mapas comportamentais, de acordo com o número de conjuntos (12) e com o fato de que foram elaborados dois mapas que representavam duas áreas distintas consideradas na investigação realizada em dois conjuntos (Restinga e Sapucaia). Observações de comportamento também foram realizadas durante uma semana (para incluir dias de semana e finais de semana), uma no turno da manhã e outra no turno da tarde, realizadas em horários com maior potencial de uso dos espaços abertos, num máximo de 14 mapas por conjunto, totalizando 138 mapas comportamentais.

Levantamentos físicos também foram realizados, acompanhados de registros fotográficos detalhados das áreas externas dos 12 conjuntos, de maneira a permitir a realização da análise das mudanças ou permanência de relações entre espaços, assim como quantificar o acréscimo de áreas construídas nos espaços abertos coletivos para diferentes propósitos (ex.: garagens, churrasqueiras, pequeno comércio e serviços, uso residencial), incluindo a marcação de elementos alterados ou incorporados às fachadas das edificações. Os dados obtidos mediante os questionários foram analisados quantitativamente através de testes estatísticos não paramétricos, como Kruskal Wallis e Spearman, por meio do programa estatístico SPSS/PC (BRYMAN; CRAMER, 1990; LAY; REIS, 2005; ROSENTHAL; ROSNOW, 1991; SOMMER; SOMMER, 1997), enquanto aqueles obtidos por meio das entrevistas foram classificados $\mathrm{e}$ analisados de acordo com a frequência, o conteúdo e o significado.

\section{Resultados}

Embora os resultados apresentados a seguir tenham sido produzidos a partir dos dados coletados nos 12 conjuntos habitacionais acima mencionados, eles tendem a sustentar aqueles produzidos em outras pesquisas (LAY, 1992; REIS, 1992).

\section{Layout do conjunto habitacional}

Os conjuntos Santo Alfredo e São Jorge ilustram o importante papel que as pequenas diferenças entre as características físicas dos espaços abertos e entre esses espaços e as moradias têm na variação de desempenho dos conjuntos. Ainda, o tipo de ordem e a relação entre espaços abertos e edificações em conjuntos habitacionais constituídos por sobrados e casas em fita, geminadas e isoladas no terreno, estabelecem uma maior ou menor clareza de hierarquia espacial, que afeta o grau de apropriação dos espaços abertos coletivos. A falta de compreensão sobre a importância dessas relações é explicitada na maioria dos projetos de conjuntos habitacionais avaliados, onde as implantações desconsideram a necessidade de clareza de definição física, confirmando ser essa uma das principais causas de mau desempenho.

Nos conjuntos com blocos de apartamento, vimos que a ausência de ordem e a falta de relação entre espaços abertos e edificações resultam em espaços não definidos hierarquicamente, ocasionando tanto em não apropriação por parte dos usuários (rejeição), com dificuldades em reconhecimento e demarcação de território, assim como em determinadas situações que têm propiciado e até mesmo incentivado o processo de invasão dos espaços abertos de conjuntos habitacionais pelos residentes e por não residentes, para fins de moradia, garagens, comércio e/ou serviços (Figura $3)$.

\begin{tabular}{l|l|l|l|l|l}
\hline \multicolumn{2}{c|}{ Casas } & \multicolumn{2}{c|}{$\begin{array}{c}\text { Sobrados com dois } \\
\text { pavimentos }\end{array}$} & $\begin{array}{c}\text { Blocos de apartamentos com } \\
\text { quatro pavimentos }\end{array}$ \\
\hline conjunto & tamanho amostra & conjunto & tamanho amostra & conjunto & tamanho amostra \\
\hline Costa e Silva & 32 & Vale Verde & 30 & Loureiro & 45 \\
\hline Guajuviras & 32 & João Vedana & 30 & Angico & 30 \\
\hline Restinga & 36 & São Jorge & 20 & Cavalhada & 33 \\
\hline & & Santo Alfredo & 24 & Guajuviras & 32 \\
\hline & & & & Sapucaia & 30 \\
\hline
\end{tabular}

Tabela 1 - Tamanhos das amostras com casas, sobrados e blocos de apartamentos 


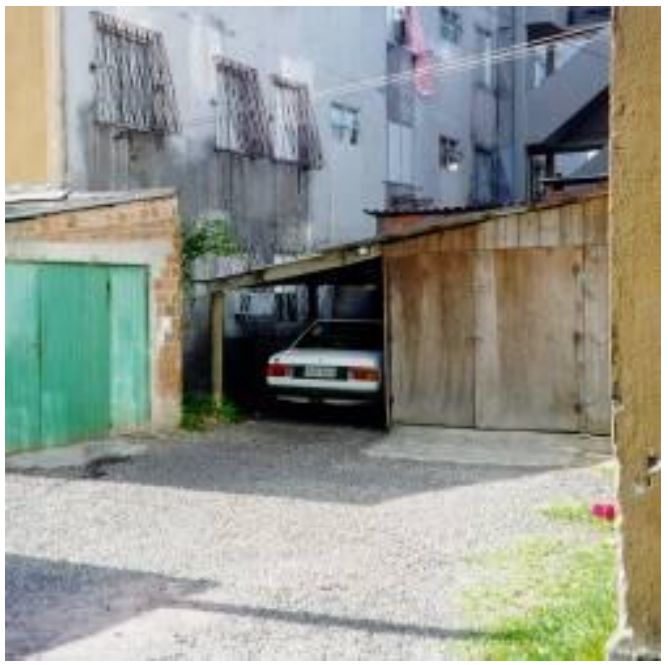

Figura 3 - Espaços abertos ocupados por edificações para fins de moradia/garagens - Sapucaia

Os estudos realizados nos diferentes conjuntos habitacionais com casas, sobrados e blocos com apartamentos permitiram a exploração das relações específicas que sugerem a maneira como o comportamento é suportado ou inibido pelo nível de clareza de definição física e social do espaço, determinada pelo layout do sítio: quanto mais legíveis os espaços abertos coletivos são definidos do ponto de vista físico e social, mais legível é o layout do sítio, e os espaços são usados de maneira mais apropriada e mais eficientemente mantidos, e vice-versa.

Logo, apesar de os projetos não determinarem o comportamento dos usuários ou o nível de satisfação em relação aos conjuntos, eles estabelecem um conjunto de qualidades físicas e espaciais que apoiam ou inibem os padrões de comportamento. O reconhecimento de território, ordem e manutenção consistente são aspectos importantes que afetam a percepção de adequação do espaço e a organização de pistas, sugerindo comportamentos (LAY, 2001, 1998; REIS, 1999). O comportamento territorial, portanto, é considerado como parte de um sistema que possibilita a organização social: organizar espaços físicos socialmente, em termos de categorias (público - acesso irrestrito; semipúblico - acesso com certo nível de restrição; semiprivado acessocom maior nível de restrição; ou privado acesso restrito) é um requisito essencial entre os residentes como meio de compreender a natureza de seu território (LAY, 1998). Assim, é possível identificar níveis de desempenho ambiental diferenciados decorrentes do layout do sítio, definido a partir da implantação das edificações, as quais proporcionam relações diferenciadas entre os espaços abertos e as edificações, afetando a qualidade ambiental e as possibilidades de apropriação, de forma a facilitar ou inibir cooperação e contato entre os moradores (LAY, 1996).

\section{Estacionamentos e garagens}

Os estacionamentos e as garagens são os aspectos mais frequentemente mencionados como insatisfatórios, tanto do ponto de vista quantitativo - por não existir espaço para todos os moradores que possuem veículos -, quanto qualitativo - a aparência é geralmente negativa, devido ao excesso de diversidade e à falta de organização das garagens e estacionamentos cobertos, construídos aleatoriamente (Figura 4). A presença de veículos nos conjuntos habitacionais tende a ser subestimada desde seu projeto: o número de proprietários de veículos é muito maior do que o número de vagas disponibilizadas nas áreas de estacionamento, provocando reações adversas entre os moradores de blocos de apartamentos e sobrados, por resultar na ocupação de espaços abertos que poderiam ser ocupados para o lazer dos moradores.

Contudo, a avaliação de adequação dos estacionamentos ou garagens apresenta diferenças expressivas entre conjuntos habitacionais com diferentes tipos arquitetônicos, revelando que conjuntos com casas respondem mais adequadamente a esse aspecto de projeto - tanto quantitativa quanto qualitativamente - do que conjuntos com blocos de apartamentos e sobrados. Nos conjuntos com casas, o uso da rua, como estacionamento tradicional, e as garagens geralmente construídas na frente ou na lateral dos lotes suprem em termos quantitativos as necessidades dos moradores, isto é, existe espaço suficiente para estacionamento de veículos. No entanto, quando garagens ou estacionamentos 
cobertos são construídos no pátio da frente dos lotes (geralmente nas casas em fita), prejudicam o desempenho funcional, o conforto luminoso, a ventilação e a visibilidade desde a moradia (Figura 5). Dos conjuntos com blocos de apartamentos e sobrados, os moradores do Angico e do Santo Alfredo são os menos insatisfeitos com as áreas de estacionamento. No Angico, por não existirem espaços abertos destinados a recreação e lazer, não foram efetuadas construções irregulares, como ocorreu em todos os outros conjuntos de blocos de apartamento, com maior ou menor intensidade. A individualização/fechamento da área destinada ao estacionamento aberto ocorreu de forma organizada, seguindo apenas o padrão preestabelecido pela marcação das vagas para carros. A localização e a qualidade das áreas de estacionamento justificam as marcadas diferenças no desempenho dos estacionamentos e de outros vários aspectos nos conjuntos São Jorge e Santo Alfredo: a área de estacionamento no São Jorge, descoberta e com piso de saibro, localizada na parte frontal do conjunto (Figura 6), afeta a aparência dos espaços abertos do conjunto, prejudica a acessibilidade visual e funcional entre a rua e o conjunto, afeta a estética e a segurança no conjunto, enquanto os estacionamentos no Santo Alfredo, cobertos e pavimentados, estão localizados nos fundos do terreno (Figura 7), com a permeabilidade visual entre a frente do conjunto e a rua preservada.

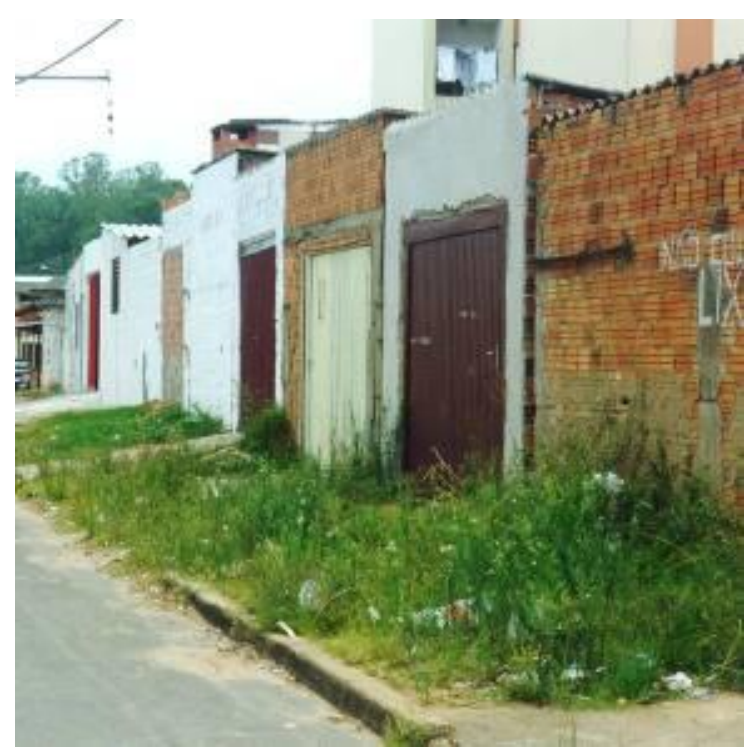

Figura 4 - Má aparência das garagens e estacionamentos construídos nos espaços abertos - Guajuviras Blocos

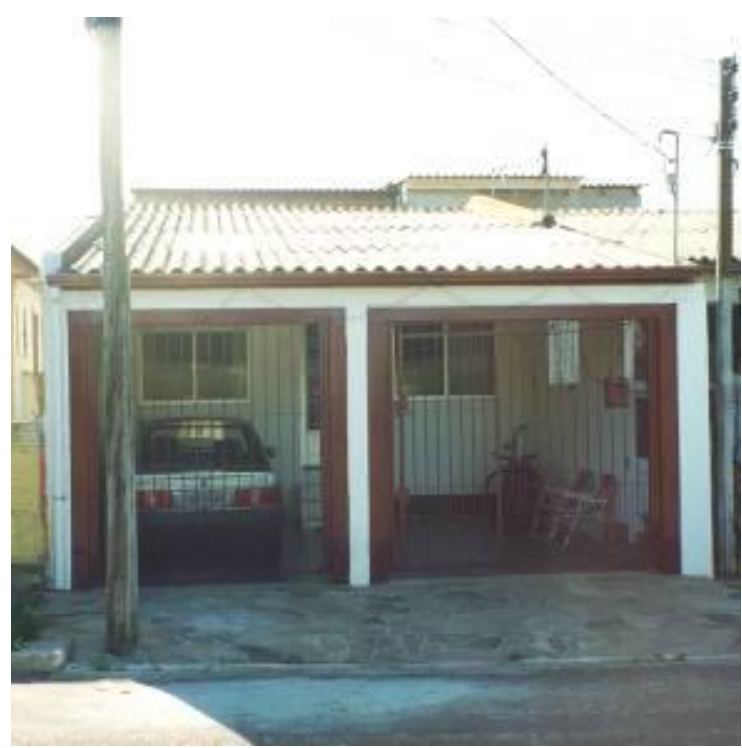

Figura 5 - Garagens construídas em frente às casas em fita prejudicando o conforto lumínico da moradia - Costa e Silva 

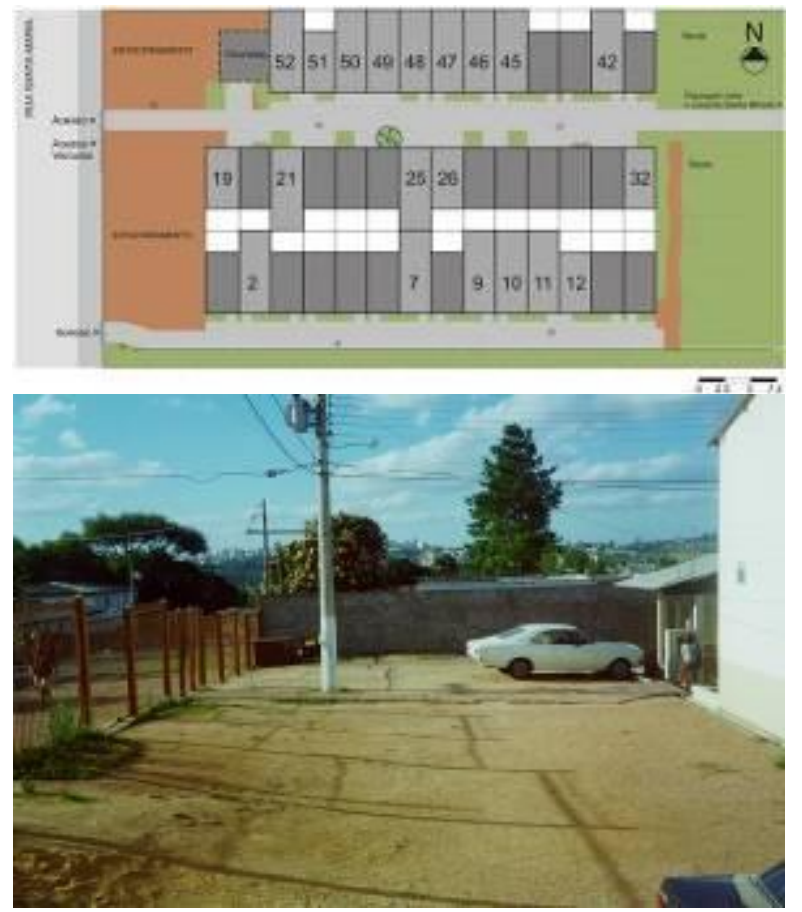

Figura 6 - Área de estacionamento de veículos na parte frontal do terreno - São Jorge
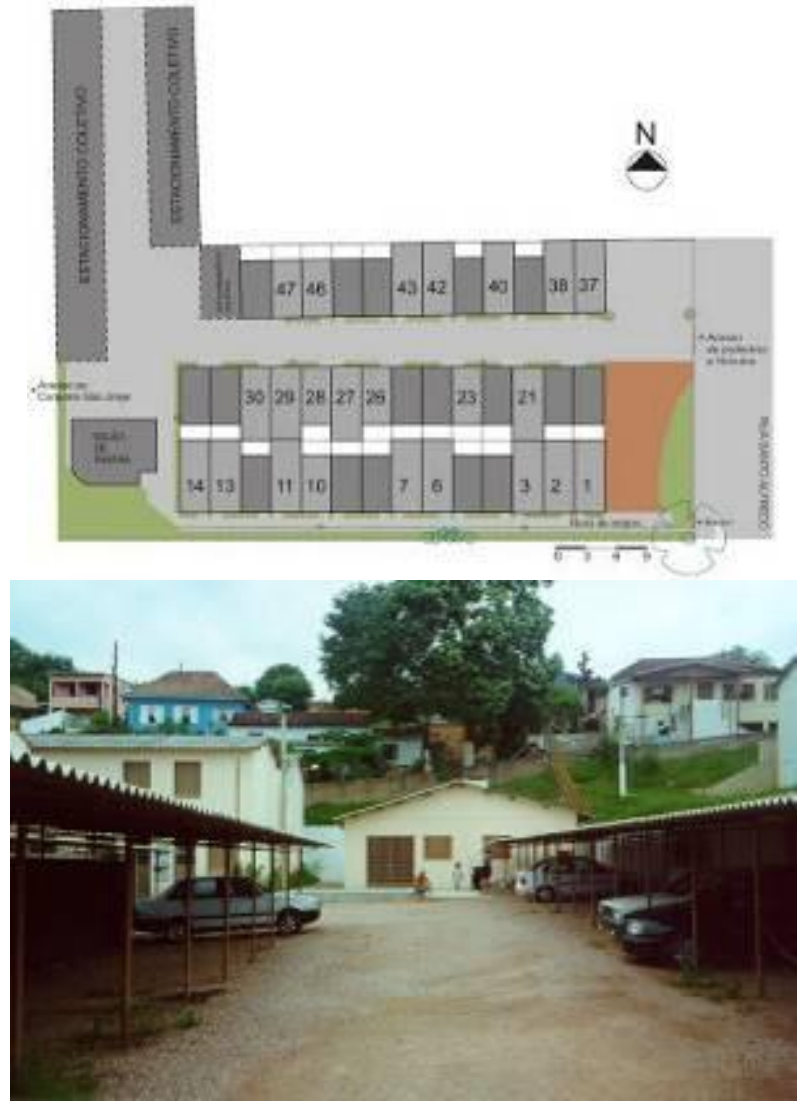

Figura 7 - Área de estacionamento de veículos nos fundos do terreno - Santo Alfredo 
Entre os principais aspectos relacionados aos estacionamentos e/ou garagens identificados como problemáticos, salientam-se:

(a) a falta de padrão construtivo, planejamento e organização;

(b) a eliminação de espaços abertos destinados a recreação e lazer;

(c) o prejuízo da acessibilidade de pedestres à moradia;

(d) a falta de vagas para todos os moradores, com as vagas tornando-se privilégio de alguns; e

(e) o prejuízo da segurança no conjunto.

Mesmo quando as garagens são inadequadas, os moradores defendem a necessidade de garagens, por dois motivos: por questões de segurança quanto a roubos, pois consideram a rua um lugar inseguro para deixar um veículo; e pela provisão de mais espaço para depósito e atividades sociais, tais como fazer churrascos com a família e amigos, embora, no caso de condomínios, a previsão de churrasqueiras coletivas poderia suprir a função social. Os estacionamentos ou garagens apresentam um impacto sobre o nível de satisfação dos moradores, indicando que, quanto mais inadequadas forem as áreas de estacionamento e/ou garagens, mais insatisfatória será a avaliação de desempenho do conjunto habitacional, e do lugar onde moram, e vice-versa. Portanto, a adequação de espaços destinados a veículos é um fator importante a ser considerado no projeto de conjuntos habitacionais, principalmente em conjuntos formados por blocos de apartamentos, sobrados e casas em fita.

\section{Equipamentos de lazer, serviços e comércio}

Os resultados obtidos indicam que a inexistência ou precariedade dos equipamentos de lazer, serviços e comércio existentes nos contextos urbanos onde muitos conjuntos habitacionais são implantados, somada à exclusão destas atividades no projeto arquitetônico dos conjuntos, faz com que, principalmente em conjuntos de maior porte, parte dos espaços abertos coletivos seja ocupada por construções com o objetivo de suprir essas necessidades. Esse fato tende a repetir-se sob a forma de alterações introduzidas na própria moradia, em conjuntos com casas. Os conjuntos investigados, ocupados há mais de 10 anos, retratam as situações descritas acima, com parte da demanda por pequeno comércio e serviços tendo sido informalmente preenchida por meio de construções irregulares ocupando os espaços abertos coletivos destinados a circulação, recreação e lazer nos conjuntos com blocos de apartamentos, e ocupando parte de algumas unidades em conjuntos com casas, o que gera um uso misto da moradia.

Ainda, a necessidade de creches, posto médico e posto policial nas proximidades dos conjuntos, e da existência de salão de festas com churrasqueira nos conjuntos das variadas tipologias não tem sido preenchida. A habitação de interesse social tende a estar localizada em áreas onde a oferta de serviços, tipos de comércio e amenidades, proporcionais ao poder aquisitivo dos moradores, tende a ser deficiente (GAMBIM, 2007), o que vem reforçar a necessidade de provisão de equipamentos de lazer, pequeno comércio e serviços em conjunto com a provisão de unidades habitacionais para a população de baixa renda. Ainda, os moradores da habitação de interesse social, em função de seu poder aquisitivo, tendem a utilizar espaços próximos da moradia, que não demandem despesas ou maiores despesas (BASSO, 2001).

\section{Aparência externa das edificações e dos espaços abertos}

Os resultados indicam que a aparência externa das edificações e dos espaços abertos do conjunto é um aspecto importante para a satisfação dos moradores com o conjunto habitacional. Nota-se que conjuntos com maior percentual de moradores insatisfeitos com o conjunto onde moram apresentam sérios problemas com a aparência das edificações e espaços abertos. Os conjuntos Cavalhada e João Vedana (Figura 8) ilustram a existência dessa relação e a importância desses fatores.

Portanto, a aparência dos conjuntos, resultante das características físicas e de manutenção das edificações e dos espaços abertos é um aspecto importante na avaliação de desempenho de conjuntos habitacionais. A aparência percebida do conjunto habitacional é fortemente afetada pelo tipo de apropriação dos espaços abertos, onde atitudes negativas em relação ao conjunto habitacional estariam motivando manifestações comportamentais também negativas, tais como mau uso e negligência na manutenção dos espaços coletivos, abertos ou edificados, e vice-versa, o que sustenta resultados de outras investigações (LAY, 1995). 

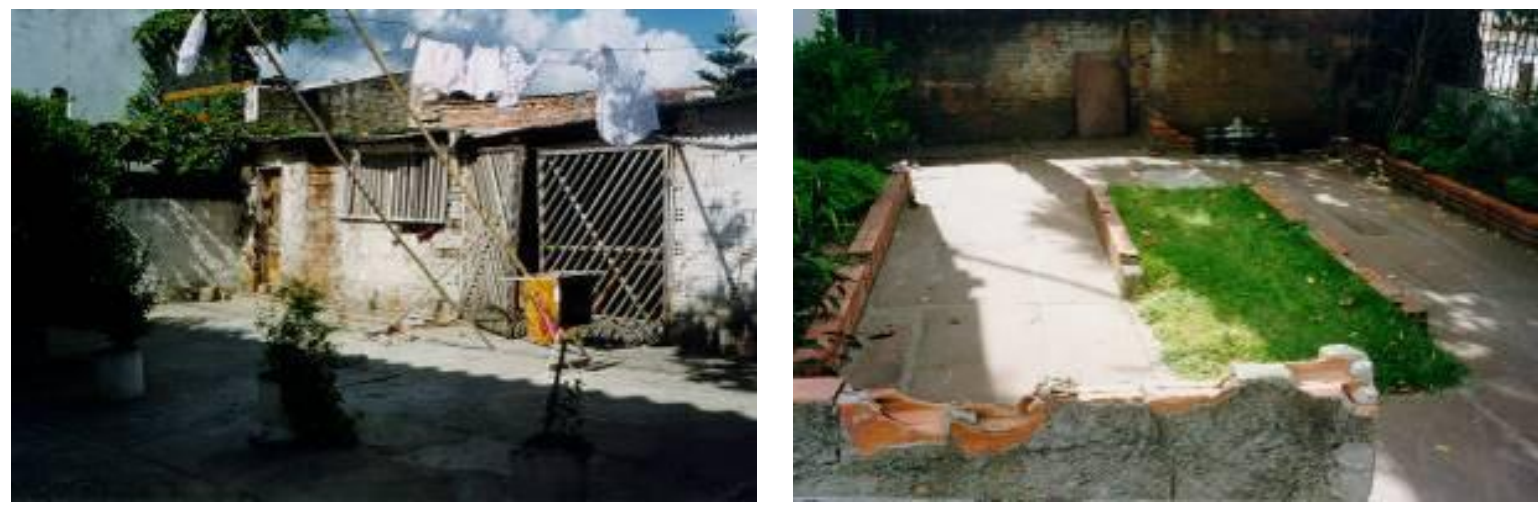

Figura 8 - Conjunto João Vedana

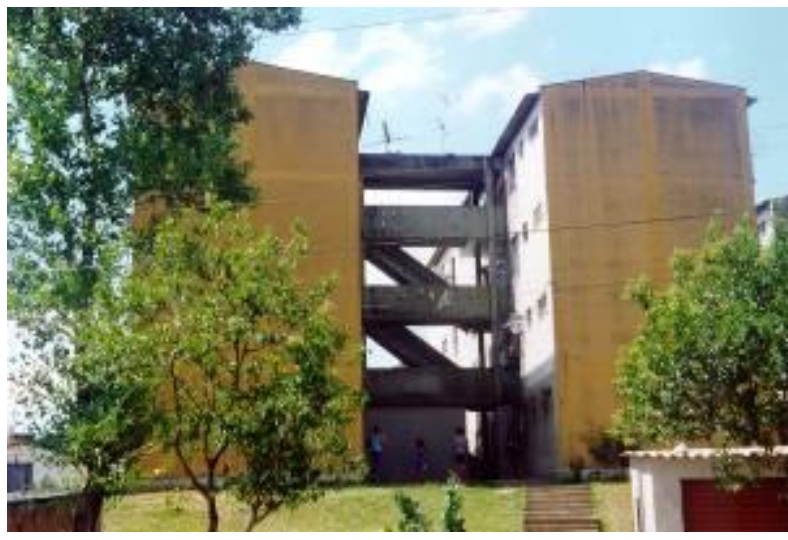

Figura 9 - Conjunto Sapucaia

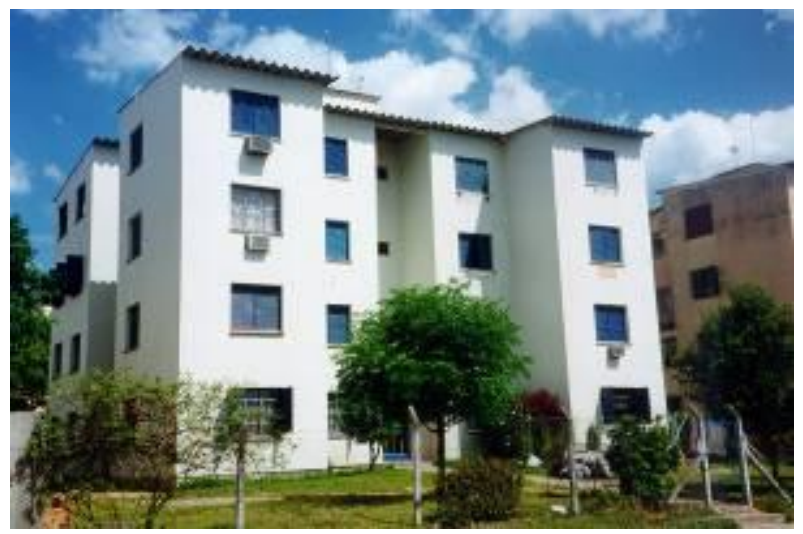

Figura 10 - Conjunto Loureiro da Silva

\section{Aparência externa do conjunto das edificações}

A aparência das edificações é um fator importante para a satisfação dos moradores com o conjunto habitacional, existindo diferenças entre tais moradores quanto aos níveis de satisfação com a aparência das edificações, que tende a ser percebida como inadequada por moradores dos distintos tipos arquitetônicos, sendo avaliada de maneira mais positiva por moradores de casas, seguida por moradores de sobrados (por exemplo, no Vale Verde, Figura 12, e no Santo Alfredo).
Nota-se que a avaliação da aparência das edificações é muitas vezes afetada pelo nível de manutenção do conjunto, como é ilustrado nos sobrados dos conjuntos São Jorge (Figura 6) e João Vedana (Figura 8), onde os moradores apresentam níveis de insatisfação aproximados aos dos moradores de blocos de apartamentos.

A aparência dos blocos de apartamentos é a mais insatisfatória (por exemplo, conjuntos Sapucaia, Figura 9, e Cavalhada, Figura 11), principalmente nos conjuntos que apresentam as piores condições de manutenção. $\mathrm{O}$ grande número de moradores 
insatisfeitos com a aparência do conjunto das edificações tende a ser explicado pelos seguintes aspectos:

(a) falta de conservação dos prédios (sem pintura e queda de reboco);

(b) ocupação dos espaços semiprivados por construções de garagens e moradias junto aos prédios;

(c) falta de manutenção e segurança das passarelas que configuram o sistema de circulação dos prédios;

(d) existência de rachaduras, que denota problemas estruturais;

(e) aspecto formal desordenado das construções irregulares; e

(f) falta de qualidade de esquadrias, que resulta na substituição das esquadrias originais por outras de melhor qualidade, porém sem padrão definido.

O sistema de circulação externo é um fator importante na aparência dos blocos e do conjunto. Nota-se que conjuntos de blocos com circulação interna (por exemplo, Guajuviras e Loureiro da Silva, Figura 10) conseguem manter um nível aceitável de manutenção em alguns prédios, o que denota a existência de organização entre os moradores e maiores possibilidades de manutenção, enquanto conjuntos com sistema de circulação externa, com passarelas, geralmente se encontram em precário estado de conservação (por exemplo, Angico, Cavalhada e Sapucaia, Figura 9). O sistema de circulação externa dos prédios estaria afetando negativamente a avaliação da aparência das edificações, em função dos problemas de manutenção gerados pelo próprio projeto, que não define quem é responsável pela manutenção da circulação que está localizada entre dois blocos e, portanto, não faz parte do corpo de "seu prédio", está no "meio do caminho" entre dois prédios, conforme mencionado por alguns moradores. Isso, somado às restrições financeiras dos moradores, afeta a manutenção das passarelas e escadas. A necessidade de manutenção das passarelas é constante, pois ficam expostas a intempéries, afetando também a segurança dos moradores.

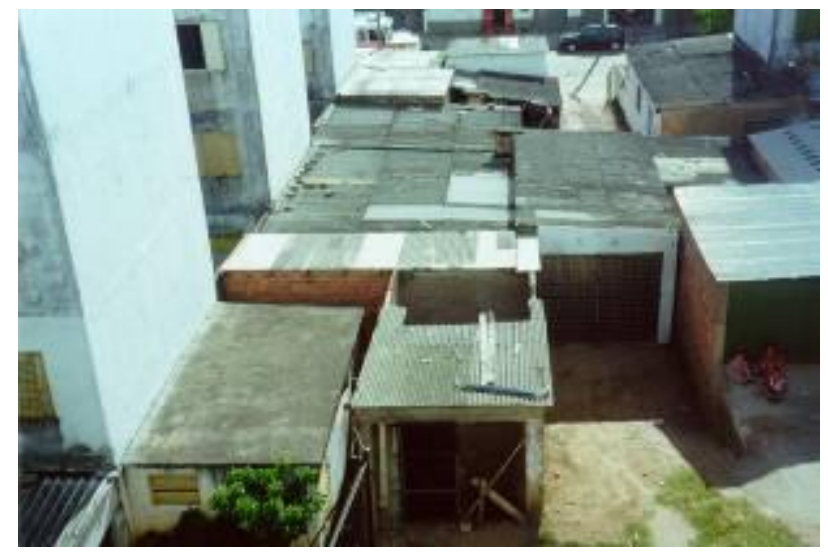

Figura 11 - Construções ilegais no Cavalhada

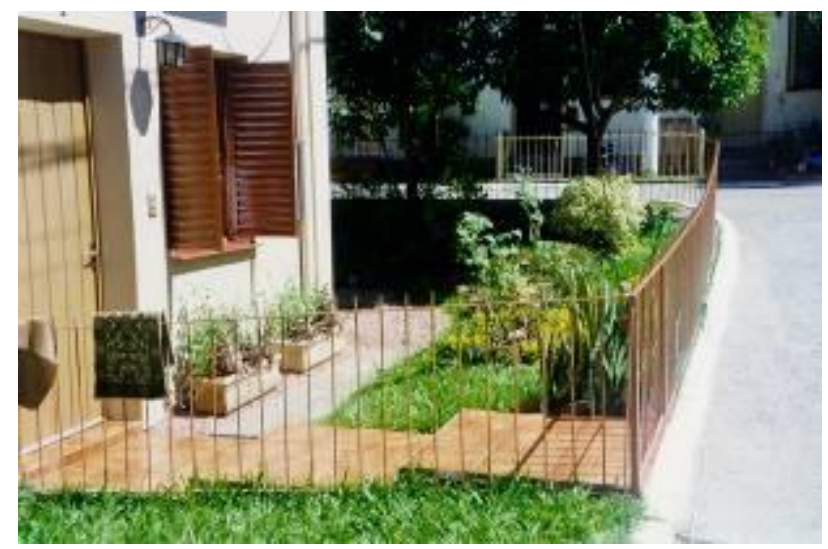

Figura 12 - Conjunto Vale Verde 


\section{Aparência dos espaços abertos}

Em geral, a aparência dos espaços abertos dos conjuntos tem uma importância maior para os moradores de blocos de apartamentos e está fortemente associada ao nível de manutenção. Áreas de recreação com equipamentos em boas condições de manutenção e aparência contribuem para uma aparência adequada dos espaços abertos. Em quatro dos cinco conjuntos com moradores mais satisfeitos com a aparência dos espaços abertos, existem áreas com mobiliário e equipamento de recreação em boas condições, como no Vale Verde, onde existe uma pracinha com equipamentos de recreação, cancha esportiva e churrasqueira coletiva, com espaços abertos bem organizados. Moradores de conjuntos com bom nível de manutenção dos espaços abertos (como no conjunto Vale Verde, Figura 12) tendem também a avaliar positivamente o desempenho do conjunto habitacional e a aparência das edificações.

Por outro lado, os moradores de sobrados mais insatisfeitos com a aparência dos espaços abertos (por exemplo, conjuntos São Jorge, Figura 6, e João Vedana, Figura 8), devido a problemas de infraestrutura e saneamento (por exemplo, sanga existente nos fundos do terreno do João Vedana), tornam-se desmotivados a fazer melhorias e até mesmo a manter os espaços abertos $\mathrm{e}$ as edificações. Ainda, a existência de construções irregulares, presentes principalmente nos conjuntos com blocos de apartamentos, afetam negativamente a aparência dos espaços abertos dos conjuntos, conforme demonstrado no Cavalhada (Figura 11), onde estão os moradores mais insatisfeitos com o conjunto e onde 55\% dos moradores estão insatisfeitos com a aparência dos espaços abertos. Contudo, o impacto normalmente pouco atraente das construções irregulares pode ser amenizado ou suplantado por melhorias realizadas nos espaços abertos do conjunto. Esse é o caso do Sapucaia, onde o possível impacto negativo das construções irregulares presentes no conjunto parece ter sido superado, conforme a avaliação pelos moradores da aparência dos espaços abertos e do próprio conjunto habitacional, pelo impacto positivo causado pelas melhorias realizadas pela Prefeitura, tais como a construção de uma pequena área de recreação (se comparada com a área total do conjunto) equipada com brinquedos e canchas esportivas, e as reformas realizadas na rótula na avenida principal.

Os dados analisados indicam que a avaliação positiva ou negativa da aparência externa das edificações e dos espaços abertos tende a estar associada aos seguintes aspectos: (a) nível de conservação das edificações: dos conjuntos investigados, nota-se que os moradores dos conjuntos com casas, seguidos daqueles em sobrados (com exceção do João Vedana), tendem a estar mais satisfeitos com o nível de conservação das edificações (decorrente das condições de pintura e limpeza), enquanto os moradores dos conjuntos com blocos de apartamentos tendem a ser os mais insatisfeitos; estes resultados são explicados, pelo menos em parte, pela necessidade de organização entre os moradores dos blocos para que a manutenção seja realizada;

(b) composição arquitetônica das edificações: os moradores de sobrados do conjunto Vale Verde são os mais insatisfeitos com o que denominam de "modelo ou estilo" das edificações, enquanto os moradores de casas no Costa e Silva são os mais satisfeitos; originalmente com um pavimento e composição arquitetônica com pouco estímulo visual, além da repetição significativa de unidades idênticas, tendendo a gerar monotonia, muitas casas nos conjuntos investigados sofreram modificações por parte dos moradores, que vieram a minimizar a monotonia existente;

(c) tipo de circulação vertical: a aparência das escadas externas com passarelas assim como dos acessos aos blocos são aspectos mencionados por moradores de blocos com apartamentos como associados à aparência das edificações;

(d) qualidade dos materiais utilizados nas edificações: principalmente a baixa qualidade das aberturas afeta negativamente a avaliação da aparência do conjunto, além de afetar negativamente a percepção de segurança;

(e) ocupações dos espaços abertos comunais nos conjuntos com blocos de apartamentos por garagens e outras construções: essas ocupações tendem a ser avaliadas como negativas pelos moradores de tais conjuntos;

(f) existência e tipo de mobiliário presente nos espaços abertos: a falta de bancos nos espaços abertos comunais é mencionada como aspecto negativo relativo à aparência, por exemplo, no conjunto Loureiro da Silva, com mobiliário depredado e sem manutenção dos espaços destinados a recreação; e

(g) presença de vegetação: esse aspecto é frequentemente relacionado à aparência positiva dos espaços abertos por moradores de todos os conjuntos; contudo, na opinião dos moradores, todos os conjuntos estão necessitando de arborização nos espaços abertos comunais e nas ruas. 


\section{Usos dos espaços abertos}

Parte-se da premissa de que, para que o projeto dos conjuntos habitacionais atenda às necessidades de uso dos espaços abertos por parte dos moradores com distintas faixas etárias, é importante que se conheça a distribuição da população-alvo nos conjuntos. Na investigação realizada, verificou-se que: a população de adultos é majoritária; a população de crianças ( 0 a 12 anos $)$ é de aproximadamente 20\%; a de adolescentes é bem menos expressiva do que a de crianças (12 a 18 anos, $12,8 \%$ ); e que a população de idosos é a menor, além de ser pouco expressiva (60 anos e acima, 6,4\%). Todavia, esse padrão de distribuição de faixas etárias não se repete necessariamente nos conjuntos caracterizados por diferentes tipos arquitetônicos, o que pode dificultar um pouco a previsão e a definição de uso dos espaços abertos nos conjuntos habitacionais. Contudo, parece que a previsão de um mínimo de espaços adequados para as diferentes faixas etárias pode evitar situações como a verificada no Guajuviras (casas), onde se concentra a maior população de adolescentes e uma das maiores populações de crianças entre os 12 conjuntos investigados, e onde não existem espaços abertos destinados à recreação infantil. Por outro lado, no Costa e Silva existem várias praças (Figura 13), uma das menores populações de crianças e a menor população de adolescentes entre os vários conjuntos. Dos conjuntos com sobrados, no Vale Verde, no João Vedana e no Santo Alfredo predomina a população adulta; no São Jorge e no Vale Verde é grande a população de adolescentes, enquanto no São Jorge e no Santo Alfredo a população infantil está acima da média total, salientando a demanda de espaços abertos para a realização de atividades de recreação. Nos conjuntos com blocos de apartamento a concentração das faixas etárias é bem diversificada.

Independentemente da proporção de crianças nos diversos conjuntos, é importante que essa faixa etária não seja tolhida em suas atividades de lazer e recreação, tão importantes para seu bem-estar e desenvolvimento sadio (COOPER-MARCUS; SARKISSIAN, 1986). Ainda, nota-se que o uso dos espaços abertos pelas crianças tende a promover o uso desses espaços pelos adultos. Por exemplo, nos conjuntos com blocos de apartamentos, o uso dos espaços abertos pelas crianças promove também o convívio entre os pais delas. Contudo, o uso dos espaços abertos pelas crianças é menos intenso em conjuntos com blocos, cujos espaços abertos são os menos utilizados pelos moradores das diversas faixas etárias, sugerindo que tais espaços nesses conjuntos não estão atraindo de maneira expressiva o uso por parte de seus moradores, incluindo as crianças. Esse fato reforça, por sua vez, a importância de um projeto dos espaços abertos que venha a contemplar as necessidades de uso dos moradores, especificamente das crianças, principalmente no tipo de conjunto com blocos investigados, onde os espaços abertos tendem a ser mais complexos em função de suas dimensões e configurações, do número de unidades atendidas pelos mesmos e das relações das edificações com tais espaços.

Existe uma tendência para aqueles moradores que utilizam os espaços abertos do conjunto a estar mais satisfeitos com o conjunto habitacional e com o lugar onde vivem, e vice-versa, reforçando a necessidade de disponibilidade de espaços abertos adequados para recreação e lazer. Por outro lado, o uso mais intenso dos espaços abertos pelas crianças não está diretamente associado a conjuntos com determinado tipo arquitetônico, tampouco com áreas específicas de recreação, já que, conforme verificado, além de o uso mais intenso por parte das crianças ocorrer no conjunto com casas geminadas na Restinga (64\% das crianças), onde existem praças e equipamentos de recreação (Figura 14), e nos sobrados (60\% das crianças no São Jorge e 50\% no Santo Alfredo), também ocorre nas casas isoladas no Guajuviras (50\% das crianças), onde não existem praças, indicando que as crianças brincam nas calçadas e nas ruas.

Os locais do conjunto habitacional mais frequentados pelas crianças tendem a ser aqueles considerados pelos pais/responsáveis como os mais adequados em termos de localização, segurança e equipamento disponível. A intensidade de uso dos espaços abertos por crianças mostra que nos conjuntos onde as condições dos espaços abertos são precárias o uso tende a diminuir. No entanto, mesmo quando espaços qualificados não são disponibilizados, a necessidade de recreação das crianças e a falta de espaço suficiente dentro da própria moradia fazem com que espaços inadequados também sejam utilizados, como, por exemplo, as ruas do setor com casas no Guajuviras. Essas condições variam de conjunto para conjunto, de acordo com o tipo de moradia e implantação, assim como das condições de manutenção dos espaços abertos comunais pelos moradores ou pela prefeitura. Os espaços mais utilizados são as ruas/calçadas, entrada do prédio onde mora, pátio do prédio (espaços semiprivados), pátio da casa, canchas e salão de festas, e praças, dependendo da disponibilidade desses espaços em cada conjunto. As atividades realizadas pelos moradores consistem em cuidar de crianças, conversar e tomar mate com vizinhos, cuidar de plantas, estender roupas, caminhar, andar de bicicleta e jogar bola. 


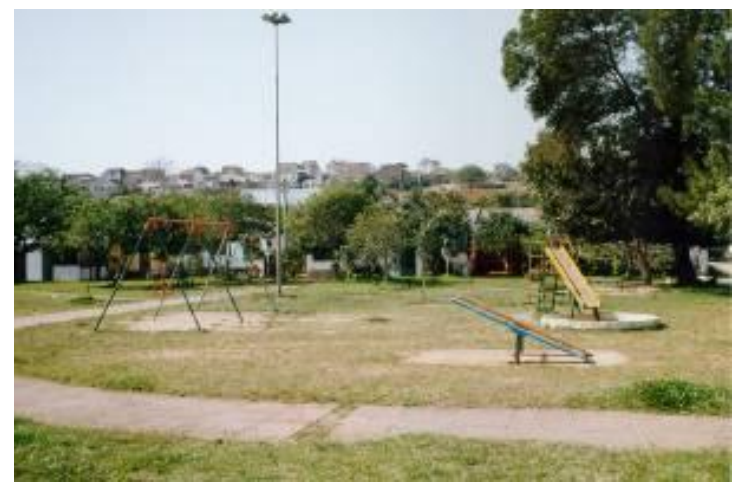

Figura 13 - Conjunto Costa e Silva

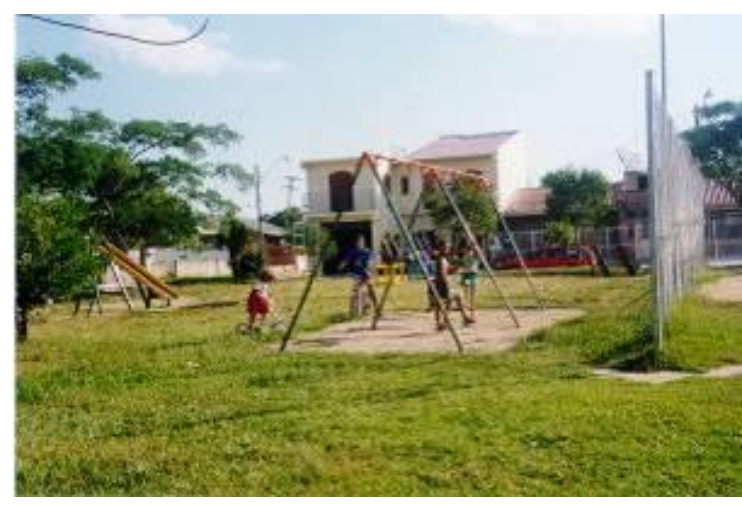

Figura 14 - Conjunto Restinga

\section{Uso de espaços abertos e tipo de moradia}

Os dados levantados indicam que moradores de casas têm expectativas de maior independência e de possuir um espaço aberto privado. Quando essas expectativas são frustradas, podem afetar negativamente o nível de satisfação com o tipo de moradia, entre outros fatores. A necessidade de uso dos espaços abertos é, algumas vezes, decorrente da falta de espaço aberto privado adequado, em virtude do aumento das áreas originais de muitas casas geminadas e consequente ocupação de quase a totalidade do lote. Entre os conjuntos com blocos de apartamentos, aqueles com moradores mais satisfeitos com o tipo de moradia (por exemplo, conjuntos Sapucaia e Loureiro da Silva) possuem o maior número de moradores com crianças usuárias de espaços abertos. Esses são também os conjuntos com blocos que possuem espaços abertos formalmente destinados a recreação. Os moradores que usam os pátios semiprivados dos blocos sentem-se mais satisfeitos com o tipo de moradia do que os que não usam, geralmente porque os espaços foram invadidos por construções irregulares.

Conforme já mencionado, o uso dos espaços abertos pode ocorrer mesmo que não existam locais específicos para recreação, indicando que a necessidade de uso pode superar a falta de condições espaciais mais apropriadas, o que não exclui, entretanto, a necessidade de provisão de tais locais nos conjuntos habitacionais. Embora os conjuntos com tipo de moradia sobrado investigados não ofereçam espaços adequados para recreação e lazer, as crianças nesses conjuntos tendem a usar mais intensamente os espaços abertos do que as crianças moradoras de blocos de apartamentos; ainda, os moradores de sobrados chegam a apresentar um uso mais intenso dos espaços abertos do que nos conjuntos com casas, com as atividades de recreação e lazer ocorrendo, predominantemente, nas áreas de circulação e estacionamento, por falta de opção. Nesse caso, a necessidade de uso sobrepõe-se à inadequação dos espaços existentes e afeta negativamente a avaliação do tipo de moradia, que possui a menor área privada construída.

As análises realizadas permitem constatar que existe relação entre o uso dos espaços abertos e o tipo de relacionamento entre os moradores em ambos os sentidos: moradores que usam os espaços abertos comunais mantêm melhor relacionamento entre si do que os que não convivem com vizinhos, assim como o mau relacionamento entre moradores pode resultar em desuso de espaços de convívio. Nota-se que o mau relacionamento, geralmente, é consequência da inadequação ou insuficiência de espaços 
destinados ao convívio e recreação, provocando conflitos entre os moradores devido ao uso alternativo de locais que podem provocar barulho excessivo, falta de privacidade ou, até mesmo, danos materiais. Embora não tenha sido identificado um padrão entre sentido de comunidade e tipo arquitetônico, nota-se a tendência de os moradores de casas manterem melhor relacionamento do que os moradores de blocos com apartamentos ou sobrados, considerando que a existência de conflitos decorrentes da inadequação dos espaços abertos é maior nos conjuntos com blocos e sobrados.

\section{Orientação espacial}

A adequação da orientação espacial no conjunto foi medida através da clareza/legibilidade do layout do conjunto em relação ao projeto original e ao tipo de alterações introduzidas pelos moradores, e consequente facilidade de acesso às unidades habitacionais percebida pelos moradores. Em geral, existe facilidade de orientação espacial nos conjuntos investigados. Todavia, embora a maioria dos moradores perceba como clara e legível a circulação e o acesso às moradias, com menos de um terço achando que é difícil, a percepção de facilidade de orientação varia entre os moradores dos diferentes conjuntos. Nos conjuntos com sobrados os moradores percebem maior facilidade de orientação, provavelmente em função de serem conjuntos com o menor número de unidades habitacionais e de constituírem condomínios com claros acessos e delimitações, com visível definição da implantação.

Moradores de casas (Restinga, Figura 15) e blocos de apartamentos (Guajuviras, Figura 16) são os que percebem maiores problemas de orientação no conjunto, considerando difícil a circulação e o acesso às suas moradias. A falta de legibilidade nesses conjuntos é consequência do número expressivo de unidades repetidas sem maiores distinções formais ou de tratamento superficial. No caso dos blocos de apartamentos a situação fica ainda mais prejudicada, pela grande quantidade de construções irregulares desordenadas, que dificultam até mesmo a circulação entre os blocos. A ocupação de espaços abertos comunais por construções irregulares, incluindo áreas de estacionamentos, tende a provocar reações adversas, resultando, por exemplo, no estreitamento dos caminhos de circulação, mudanças na hierarquia espacial e aparência do conjunto, afetando negativamente a acessibilidade, legibilidade e orientação no conjunto habitacional.
A orientação no conjunto é facilitada pela existência de pontos de referência, tais como localização da parada de ônibus ou de outro equipamento urbano em relação à moradia, identificação das ruas internas e numeração. Por exemplo, nos conjuntos Loureiro da Silva, Cavalhada e em todos os conjuntos com casas a orientação através da numeração é dificultada pelo fato de alguns blocos não possuírem numeração e de não haver padronização na numeração das casas. A orientação no conjunto é dificultada quando este é dividido em categorias, tais como em setores e quadras. Problemas com identificação de setores são mais fortemente identificados nos conjuntos Restinga (casas), Guajuviras (casas), Guajuviras (blocos), Cavalhada e Vale Verde. Nos conjuntos com blocos de apartamentos a inexistência de sinalização no percurso também dificulta a orientação, devido à falta de referências que poderiam ter sido parte do projeto arquitetônico ou devido à intensidade de construções irregulares que dificultam ou impedem a visibilidade.

\section{Conclusões}

Os resultados apresentados exemplificam a relevância da consideração de aspectos de projeto para que a habitação de interesse social seja socialmente sustentável. Assim, é possível fazer recomendações projetuais adequadas às necessidades dos usuários e, logo, que venham qualificar o projeto da habitação de interesse social. Uma vez que tais propostas estão baseadas em investigações que consideram a realidade das relações entre os espaços habitacionais e seus usuários, estas apresentam um potencial significativo em responder adequadamente aos moradores e a tornar a habitação de interesse social socialmente sustentável. Portanto, com base nos resultados apresentados, recomenda-se em relação à necessidade de garagens e estacionamentos:

(a) considerar a possibilidade de 1 vaga de estacionamento para cada unidade habitacional de conjuntos de sobrados e blocos de apartamentos;

(b) no caso de estacionamentos cobertos ou garagens, considerá-los como parte integrante do projeto arquitetônico do conjunto, de maneira que exista uma compatibilidade formal entre os mesmos, através de um padrão construtivo, planejamento e organização, e que tais garagens ou estacionamentos possam abrigar churrasqueiras e servir como depósitos; 

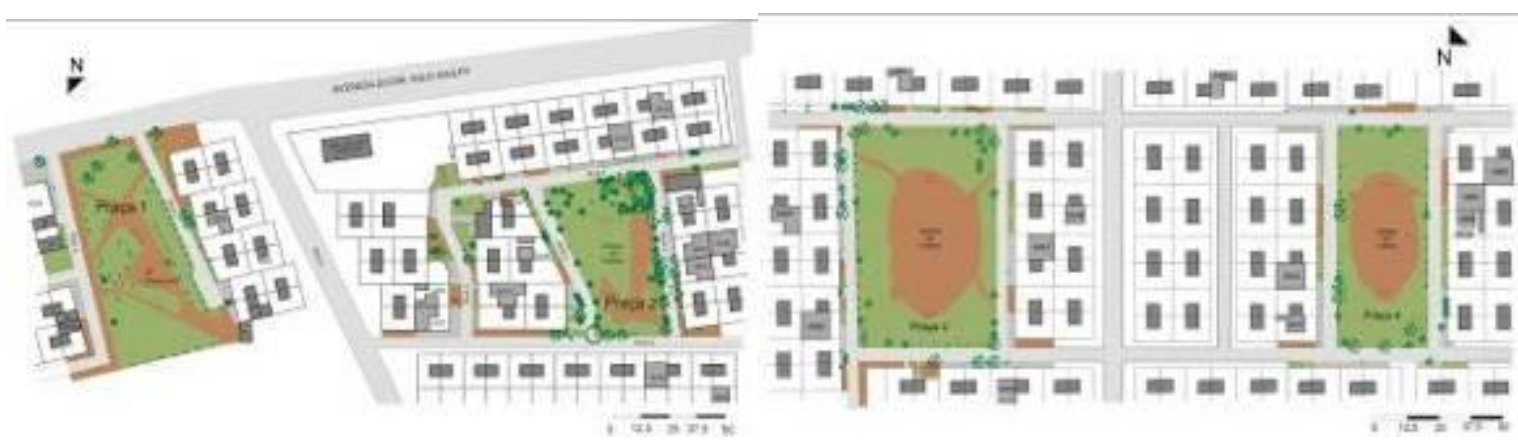

Figura 15 - Conjunto Restinga

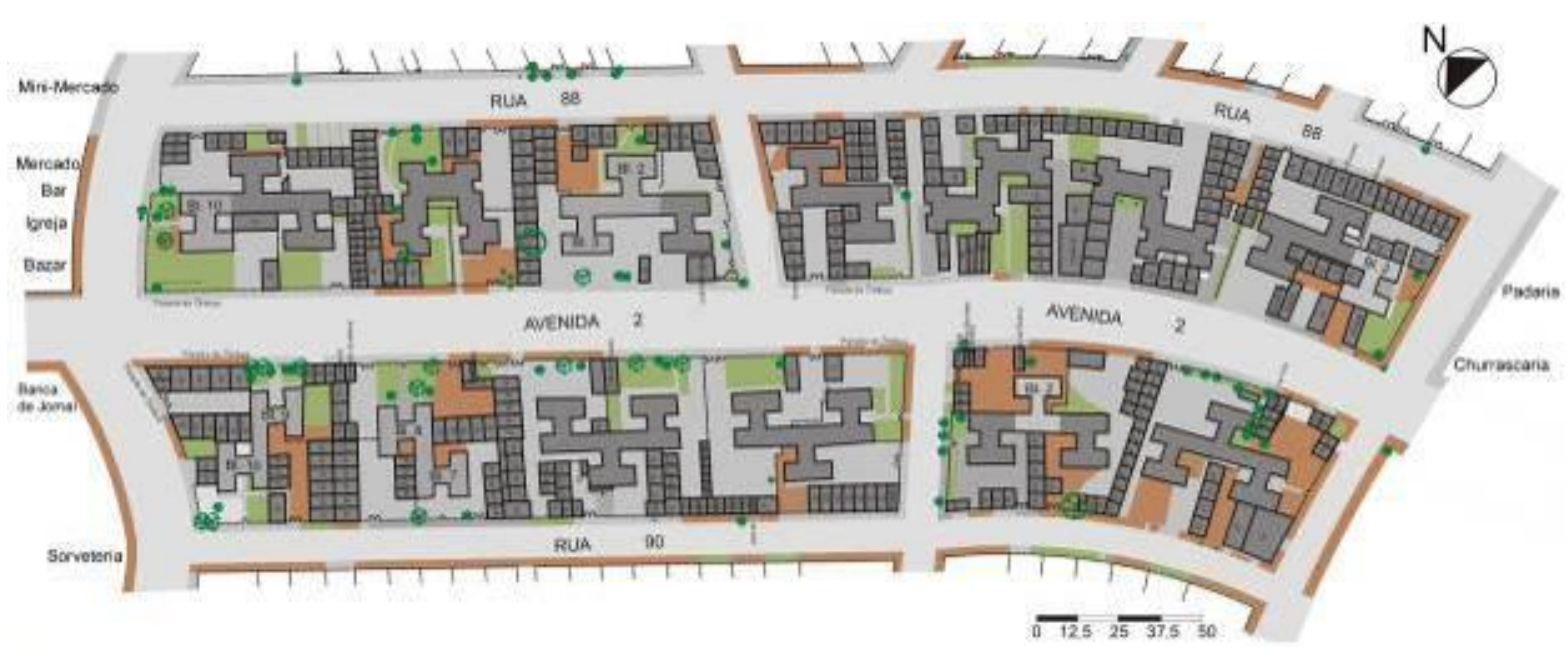

Figura 16 - Conjunto Guajuviras

(c) especialmente nos conjuntos com blocos de apartamentos, dificultar ou impossibilitar a ocupação de espaços de uso coletivo para a construção de garagens e estacionamentos, mediante uma clara definição física e de uso desses espaços, impedindo que espaços abertos destinados a recreação e lazer sejam eliminados;

(d) considerar a localização e a qualidade das áreas de estacionamento, de maneira que não afetem negativamente a aparência e a segurança dos espaços abertos do conjunto;

(e) considerar a localização das áreas de estacionamento de maneira a garantir a acessibilidade visual e funcional entre a rua e o conjunto; e

(f) prover áreas de estacionamento adequadamente pavimentadas, evitando piso de saibro; e

(g) em conjuntos com casas, prever no projeto arquitetônico a ocupação lateral do lote e inibir a ocupação frontal, para garantir o conforto luminoso da moradia.

Com relação aos equipamentos de lazer, serviços e comércio, é sugerido: (a) prover o conjunto com pequeno comércio, serviços e áreas de recreação e lazer, conforme a existência e a adequação deles no contexto urbano considerado;

(b) prever a existência de creche e de salão de festas com churrasqueira;

(c) prever a existência de posto médico e posto policial no próprio conjunto, caso sejam inexistentes no entorno imediato;

(d) considerar a localização dos equipamentos comunitários, serviços e comércio em áreas com acesso direto às vias de circulação para pedestres e veículos;

(e) apresentar equipamentos comunitários, serviços e comércio com atributos formais compatíveis aos das edificações com as habitações; $\mathrm{e}$

(f) considerar a possibilidade de integrar parte ou a totalidade dos equipamentos comunitários, serviços e comércio aos tipos arquitetônicos das moradias.

Com relação à aparência das edificações, é recomendável: 
(a) considerar a manutenção das fachadas das edificações, que pode ser facilitada pela adequação do sistema construtivo, dos materiais, detalhes arquitetônicos e demais características formais adotadas no projeto, e pelo grau de dificuldade em manter as superfícies edificadas; esse grau de dificuldade, no caso dos blocos de apartamentos, está relacionado à capacidade de organização dos moradores, que, por sua vez, é facilitada pela existência de um número menor de apartamentos no bloco;

(b) incluir esquadrias de qualidade, que minimizam a possibilidade de troca;

(c) evitar sistema de circulação externo com passarelas nos blocos com apartamentos, cuja manutenção é particularmente dificultada por suas características formais e construtivas, pela exposição às intempéries e pela necessidade de organização dos moradores para que tal manutenção se efetive;

(d) organizar a relação entre os espaços edificados e os espaços abertos, por meio de conexões visuais e funcionais, assim como estabelecer uma hierarquia territorial dos espaços abertos, de forma que os espaços semiprivados, semipúblicos ou públicos não sejam ocupados por garagens e demais construções irregulares junto às edificações originais, que tendem a gerar uma desordem formal em função das diferenças entre os elementos presentes nessas construções, assim como entre estes e aqueles nas edificações originais; e

(e) evitar a repetição excessiva de edificações com composições arquitetônicas com muito pouco ou nenhum estímulo visual, de maneira que o conjunto resulte monótono pela falta de sensibilização da percepção visual dos observadores.

Com relação à aparência dos espaços abertos, é importante:

(a) evitar a incorporação ou a adjacência a áreas problemáticas, com problemas de saneamento e de difícil manutenção e tratamento por parte dos moradores;

(b) estabelecer uma hierarquia territorial com uma clara definição sobre quem controla cada tipo de espaço, como forma de impedir a ocupação de espaços comunitários por construções para fins privados;

(c) incluir mobiliário e equipamento de recreação (p. ex., brinquedos, churrasqueiras e canchas esportivas) em áreas com clara definição e controle territorial, de forma a garantir a manutenção adequada; (d) considerar a inclusão de vegetação (p. ex., jardins, flores, arbustos, árvores) adequada às características dos solos, aos usos previstos para os espaços abertos e às relações com as edificações, principalmente em espaços privados, semiprivados e semipúblicos, bem conectados visual e funcionalmente às edificações, de maneira a facilitar o controle e a manutenção da vegetação e a minimizar a possibilidade de vandalismo;

(e) especificamente, considerar a possibilidade de arborização dos caminhos para pedestres, por razões estéticas, além das de conforto térmico; e

(f) considerar a possibilidade de personalização dos espaços abertos com jardins privados ou semiprivados, principalmente junto aos acessos às edificações.

Com relação ao uso dos espaços abertos, recomenda-se:

(a) prover espaços adequados e suficientes, com clara definição e controle territorial, destinados ao convívio e recreação dos moradores, possibilitando a recreação e a interação social entre os moradores, principalmente quando o tipo arquitetônico é caracterizado por bloco com apartamentos ou sobrados;

(b) prover espaços para atividades passivas ( $\mathrm{p}$. ex., conversar, tomar chimarrão, contemplar a paisagem e o movimento) e ativas (p. ex., jogar bola, jogos de crianças), considerando o conforto térmico de tais espaços no verão (sombreamento) e no inverno (incidência solar, pelo menos parcial);

(c) especialmente para as crianças menores, prover espaços onde a segurança é reforçada: pelo controle de acesso a eles; pelas conexões visuais e funcionais às moradias; pela proteção de locais que possam causar acidentes, tais como canchas de esporte, desníveis abruptos e barrancos; e

(d) apresentar espaços abertos coletivos com clara definição física e de uso; evitar a utilização simultânea de uma via para circulação de pessoas e veículos, sem que existam calçadas para a circulação de pedestres, como acontece nos sobrados investigados.

Com relação à orientação espacial de moradores e visitantes nos conjuntos, é sugerido:

(a) dificultar a ocupação de espaços abertos comunais por construções irregulares, incluindo áreas de estacionamentos, que tendem a provocar, especialmente nos conjuntos com blocos com apartamentos, estreitamentos dos caminhos de circulação, mudanças na hierarquia espacial e nas referências visuais no conjunto;

(b) considerar o número de unidades habitacionais no conjunto, já que a dificuldade de orientação 
tende a aumentar com o aumento no número de unidades;

(c) evitar a repetição excessiva de edificações sem maiores distinções formais ou de tratamento superficial, procurando criar referências visuais através da própria arquitetura das edificações (p. ex., através de diferenças em altura);

(d) estabelecer claros acessos, a partir dos espaços públicos, semipúblicos e semiprivados, de circulação de veículos e pedestres, além de claras delimitações das áreas residenciais privadas, semiprivadas e semipúblicas;

(e) considerar a possibilidade de adotar pontos de referência em relação às moradias, através de equipamentos urbanos (p. ex., parada de ônibus), ou edificações com uso especializado (p. ex., escola); e

(f) identificar as ruas dos conjuntos com nomes, e as edificações, com numeração padronizada, claramente visíveis a partir do espaço público da rua; basear a identificação das edificações no nome das ruas e na numeração das edificações, evitando a divisão do conjunto em categorias, tais como setores e quadras, que tendem a dificultar a orientação.

Concluindo, o conhecimento obtido a partir da identificação dos aspectos de projeto que afetam positiva ou negativamente as atitudes e comportamentos dos usuários tem aplicação tanto na melhoria de conjuntos existentes quanto em novos projetos habitacionais. Este estudo contribui para o conhecimento sobre o projeto da habitação de interesse social e da sustentabilidade social ao apresentar certos aspectos de projeto relacionados ao exterior das unidades habitacionais, alguns dos quais corroborando resultados de outros estudos (referenciados anteriormente), e ao evidenciar a necessidade da consideração de aspectos de projeto para a sustentabilidade social da habitação. Segue que a habitação de interesse social só pode ser socialmente sustentável se não for pensada exclusivamente em termos quantitativos, apenas como provisão de um número de unidades habitacionais, mas pensada como habitação qualificada, isto é, que satisfaça as necessidades de seus moradores e qualifique suas vidas, através de projetos arquitetônicos adequados.

\section{Referências bibliográficas}

BALDWIN, J. Urban Criminality and the "Problem" Estate. Tonbridge, Knight Moo: Local Government Studies, 1975.
BASSO, J. M. Investigação de Fatores que Afetam o Desempenho e Apropriação de Espaços Abertos Públicos. 2001. $216 \mathrm{f}$.

Dissertação (Mestrado em Planejamento Urbano e Regional) - Escola de Engenharia, Universidade Federal do Rio Grande do Sul, Porto Alegre, 2001.

BLAKE, P. Form Follows Fiasco: why modern architecture hasn't worked. Boston: Little Brown, 1977.

BLAY, Eva A. Eu Não Tenho Onde Morar: vilas operárias na cidade de São Paulo. São Paulo: Nobel, 1985.

BRYMAN, A.; CRAMER, D. Quantitative Analysis for Social Scientists. Londres: Routledge, 1990.

COLEMAN, A. Utopia on Trial: vision and reality in planned housing. Londres: Hilary Shipman, 1985.

COOPER-MARCUS, C.; SARKISSIAN, W. Housing as If People Mattered. Berkeley: University of California, 1986.

FRANCESCATO, G. et al. Residents'

Satisfaction in HUD-Assisted Housing: design and management factors. Washington, DC: U.S. Department of Housing and Urban Development, 1979.

GAMBIM, P. S. A Influência de Atributos Espaciais na Interação Entre Grupos Heterogêneos em Ambientes Residenciais. 2007. 320 f. Dissertação (Mestrado em Planejamento Urbano e Regional) - Escola de Engenharia, Universidade Federal do Rio Grande do Sul, Porto Alegre, 2007.

KELLET, P. Killingworth Towers: what went wrong? Open House International, Newcastle Upon Tyne, v. 12, n. 4, p. 4-11, 1987.

KRUSE, L. Evolving the Concept of Sustainability. In: CONFERENCE OF THE INTERNATIONAL ASSOCIATION FOR PEOPLE-ENVIRONMENT STUDIES, 14., 1997, Stockholm. Proceedings... Estocolmo: Royal Institute of Technology (KTH), The Department of Architecture and Townplanning, 1997. v. 1, p. 1012.

LAY, M. C. Effects of Dwelling Type Diversity on Appropriation of Outdoor Spaces and Community Formation in Housing Schemes. In: CONFERENCE OF THE ENVIRONMENTAL DESIGN RESEARCH ASSOCIATION, 32., 2001, Edimburgo, Proceedings... Edimburgo: EDRA, 2001. v. 1, p. 60-67. 
LAY, M. C. Site Layout, Territorial Organization and Social Behavior in Residential Environments. In: INTERNATIONAL ASSOCIATION FOR PEOPLE-ENVIRONMENT STUDIES, 15., 1998, Eindhoven, Proceedings... Eindhoven: IAPS, EIRASS, Eindhoven University of Technology, 1998. p. 187-201.

LAY, M. C. Relationships Between Site Layout and Spatial Behaviour in Low Income Housing Schemes. In: CONFERENCE OF THE INTERNATIONAL ASSOCIATION FOR PEOPLE-ENVIRONMENT STUDIES, 14., 1996, Estocolmo. Proceedings... Estocolmo: Royal Institute of Technology (KTH), The Department of Architecture and Townplanning, 1996. v. 1. p. 398409.

LAY, M. C. O Impacto da Qualidade da Habitação Popular na Imagem Urbana. In: ENCONTRO NACIONAL DE TECNOLOGIA NO AMBIENTE CONSTRUÍDO, 6., 1995, Rio de Janeiro. Anais... Rio de Janeiro: ANTAC, 1995. v. 1. p. 313-318.

LAY, M. C. Responsive Site Design: user environmental perception and behaviour. 1992. 290 f. Tese (Doutorado em Arquitetrura) - PostGraduate Research School, School of Architecture, Oxford Brookes University, Oxford, 1992.

LAY, M. C.; REIS, A. Análise Quantitativa na Área de Estudos Ambiente-Comportamento. Revista Ambiente Construído, Porto Alegre, v. 5, n. 2, p. 21-36, abr./jun. 2005.

LEEDY, P. D. Practical Research: planning and design. Nova York: MacMillan, 1989.

LEGENDRE, A. Social Sustainability and Changes in Environments Designed for Young Children: the case of the French day-care centers. In: MOSER, G. et al. (Ed.). People, Places, and Sustainability. Gottingen, Alemanha: Hogrefe \& Huber Publishers, 2003. p. 243-254.

LEITE, F. L. Contribuições para o Gerenciamento dos Requisitos do Cliente em Empreendimentos do Programa de Arrendamento Residencial. 2005. 179 f. Dissertação (Mestrado em Engenharia Civil) Escola de Engenharia, Universidade Federal do Rio Grande do Sul, Porto Alegre, 2005.

MINISTÉRIO DAS CIDADES. Ministro Anuncia Novo Déficit Habitacional Durante FUM5. Disponível em: <http://www.cidades.gov.br/noticias/ministroanuncia-novo-deficit-habitacional-de-5-8durantefum $5 /$ ?searchterm $=$ deficit $\% 20$ habitacional\%202009>. Acesso em: 21 jun. 2010a.

\section{MINISTÉRIO DAS CIDADES. Déficit}

Habitacional Cai Novamente: de $14,9 \%$ para $14,5 \%$ do total de domicílios. Disponível em: $<$ http://www.cidades.gov.br/noticias/deficithabitacional-cai-novamente-de-14-9-para-14-5-dototal-de-domicilios/>. Acesso em: 12 abr. 2010b.

MONTGOMERY, R. High Density, Low-Rise House and Changes in the American Housing Economy. In: DAVIS, S. (Ed.). The Form of Housing. Nova York: Van Nostrand Reinhold, 1977. p. 83-111.

OKTAY, D. Sustainability of Housing Environments: assessments in cypriot settlements. In: CONFERENCE OF THE ENVIRONMENTAL DESIGN RESEARCH ASSOCIATION, 30., 1999, Orlando, Proceedings... Orlando: EDRA, 1999. v. 1, p. 147-158.

REIS, A.; LAY, M. C. As Técnicas de APO como Instrumento de Análise Ergonômica do Ambiente Construído. Gramado, RS: Curso III Encontro Nacional - I Encontro Latino-Americano de Conforto no Ambiente Construído, ANTAC Associação Nacional de Tecnologia do Ambiente Construído, 1995.

REIS, A. Aparência, Qualidade e Habitação Sustentável. In: ENCONTRO NACIONAL DE TECNOLOGIA DO AMBIENTE CONSTRUÍDO, 9., 2002, Foz do Iguaçu, PR. Anais... Foz do Iguaçu: ANTAC, 2002. p. 1105-1112.

REIS, A. Open Spaces of Housing Environments: lack of territorial control, maintenance, use and appearance. In: ENVIRONMENTAL DESIGN RESEARCH ASSOCIATION CONFERENCE, 13., 1999, Orlando, Florida. Proceedings... Orlando, Florida: EDRA, 1999. p. 179-187.

\section{REIS, A. Mass Housing Design, User}

Participation and Satisfaction. 1992. 361 f. Tese (Doutorado em Arquitetura) - Post-graduate Research School, School of Architecture, Oxford Brookes University, Oxford, 1992.

ROSENTHAL, R.; ROSNOW, R. L. Essentials of Behavioral Research: methods and data analysis. Nova York: McGraw-Hill, 1991.

RYKWERT, Joseph. A Sedução do Lugar: a história e o futuro da cidade. São Paulo: Martins Fontes, 2004. 
SADAN, E.; CHURCHMAN, A. Global Sustainability and Community Empowerment. In: CONFERENCE OF THE INTERNATIONAL ASSOCIATION FOR PEOPLE-ENVIRONMENT STUDIES, 14., 1996, Stockholm. Proceedings... Stockholm: Royal Institute of Technology (KTH), The Department of Architecture and Townplanning, 1996. v. 1, p. 184-192.

SERRA, G. G. Post-Occupancy Evaluation at the Urban Scale in Brazil. In: PREISER, W. F. (Ed.). Building Evaluation, Nova York: Plenum Press, 1989. p. 307-315.

SILVA, V. G. Indicadores de Sustentabilidade de Edifícios: estado da arte e desafios para desenvolvimento no Brasil. Ambiente Construído, Porto Alegre, v. 7, n. 1, p. 47-66, jan./mar. 2007.
SOMMER, B.; SOMMER, R. A Practical Guide to Behavioral Research. Nova York: Oxford University Press, 1997.

VAN DALEN, D. B. Understanding Educational Research. Londres: McGraw-Hill, 1979.

WHITE, S. S.; ELLIS, C. Sustainability, the Environment, and New Urbanism: an assessment and agenda forr. Journal of Architectural and Planning Research, Chicago, v. 24, n. 2, p. 125142, verão 2007.

\section{Agradecimentos}

Agradecimentos são prestados à Caixa Econômica Federal (CEF) pelo apoio financeiro para a realização da pesquisa. 